Vernez, D.; Wognin, B.; Tomicic, C.; Plateel, G.; Charrière, N.; Bruhin, S.

Cyclododecane exposure in the field of conservation and restoration of art objects. International Archives of Occupational and Environmental Health, 84(4) :371-374, 2011.

\begin{tabular}{|l|l|}
\hline Postprint version & Final draft post-refereeing \\
\hline Journal website & $\underline{\text { http://www.springerlink.com/content/101165 }}$ \\
\hline Pubmed link & $\underline{\text { http://www.ncbi.nlm.nih.gov/pubmed/21082189 }}$ \\
\hline DOI & $\underline{10.1007 / \text { s00420-010-0596-1 }}$ \\
\hline
\end{tabular}




\section{Cyclododecane exposure in the field of conservation and}

\section{restoration of art objects}

David Vernez ${ }^{1}$, Barthélémy Wognin ${ }^{2}$, Catherine Tomicic $^{1}$, Gregory Plateel $^{1}$, Nicole Charrière ${ }^{1}$, Stefanie Bruhin ${ }^{3}$

${ }^{1}$ Institute of Work and Health, 1011 Lausanne, Switzerland

${ }^{2}$ Yopougon Hospital, Occupational medicine Dpt., 21 BP 632 Abidjan, Ivory Coast

${ }^{3}$ The Swiss National Museum, Collection Center, 8910 Affoltern am Albis, Switzerland

\section{Correspondence Address}

David Vernez, Institute of Work and Health, 1011 Lausanne, Switzerland

David.vernez@hospvd.ch

Tel. 0041213147451

Fax 0041213147420 


\section{Abstract}

Purpose Recent work practices in conservation and restoration involve the use of Cyclododecane (CDD, CAS 294-62-2) to protect fragile artifacts during their handling or transportation. Little is known about its toxicity and no previous exposure has been reported. A short field investigation was conducted to characterize exposure conditions to both CDD vapors and aerosols.

Methods Measurements were conducted in the laboratory of conservation and restoration of the archeological service in Bern (Switzerland). 3 indoor and 4 outdoor typical work situations, either during brush or spray gun applications, were investigated. Measurements were performed on charcoal adsorbent tube and analyzed by a gas chromatograph equipped with a flame ionization detector

Results Measurements have been conducted during both brush and spray gun applications. Indoor exposures were of $0.75-15.5 \mathrm{mg} / \mathrm{m}^{3}$, while outdoors exposures were $19.5-53.9 \mathrm{mg} / \mathrm{m}^{3}$. Exposures appear to be extremely localized due to both physico-chemical properties and application methods of the CDD. Vapor exposure increases dramatically with the confinement of the workplace.

\section{Conclusion}

Preventive measures should be undertaken to limit as much as possible these exposures. Field work in confined areas (ditches, underground) is of particular concern. CDD-coated artifacts or materials should be stored in ventilated areas to avoid delayed exposures.

Keywords : cyclododecane, conservation, restoration, air sampling 


\section{Introduction}

Cyclododecane (CDD), an alicyclic saturated hydrocarbon $\left(\mathrm{C}_{12} \mathrm{H}_{24}\right.$, CAS 294-62-2), highly hydrophobic, and chemically stable, sublimes slowly at room temperature (vapor pressure: 0.07 $\mathrm{hPa}$ at $\left.20^{\circ} \mathrm{C}\right)$.

CDD is primarily used, since 1995, as an intermediate in industry (production of polymers, perfumes or cleaning agents). Interestingly, CDD has also been found to be an useful agent in conservation and restoration of art objects as wall paintings, easel paintings, paper and textile. It also quickly finds its way into in the field of archaeology as an adhering support material for fragile in situ artifacts (Rowe and Rozeik, 2008). One of its key advantages is that it evaporates by itself over a period of weeks or months, leaving no residue and without the need of any further intervention. CDD is applied on fragile in situ artifacts, providing temporary consolidation, sealing or support during their handling, or transportation. Preparation consists of heating crystalline cyclododecane to above $60^{\circ} \mathrm{C}$ in a bowl until melted and then applying it using brushes, impregnated cotton gazes, or other tools to encase an archaeological object. For larger and more complex archeological finds a spray technique has been developed that allows an even and rapid application.

Because CDD was considered as an intermediate, little attention has been given to its toxicity. No long-term toxicological data is available and short-term toxicological studies are scarce. Some ecotoxicological data exist, although QSAR model and experimental data are contradictory (ECHA, 2008). An oral $L D_{50}$ in mouse of $>10,000 \mathrm{mg} / \mathrm{kg}$ of bodyweight, suggesting low toxicity, has been reported in the only mammal study published by Irie et al. (1973). 
A NOAEL value of $250 \mathrm{mg} / \mathrm{kg}$ of bodyweight, based on a repeated dose toxicity study carried out on rats, is mentioned in the European Commission's IUCLID dataset (ECHA 2010). Currently, there are no recommended Permissible Exposure Limits (PELs) and no reference methods for CDD sampling and analysis. Tentative comparisons can be drawn with similar substances or families. Cyclohexane, which has an acute oral LD50 in rats of $>5000 \mathrm{mg} / \mathrm{kg}$ of bodyweight, has a TLV of $350 \mathrm{mg} / \mathrm{m}^{3}$ according to ACGIH and $700 \mathrm{mg} / \mathrm{m}^{3}$ according to German Federal Institute for Occupational Safety and Health (BAuA). Moreover, according to the BauA technical guideline document on aliphates mixtures (TRGS 900), a TLV of $600 \mathrm{mg} / \mathrm{m}^{3}$ is suitable for C9-C15 aliphates.

Overall, the scarcity of the toxicological data makes the picture uncertain and reference value as high as several hundred $\mathrm{mg} / \mathrm{m}^{3}$ may be inadequate. Moreover, adverse health effects immediately after exposures to CDD have been recently reported, suggesting a lower short-term threshold. Several students from the department of conservation and restoration of archaeological cultural objects at the University of Applied Sciences in Berlin ${ }^{1}$ developed symptoms such as eye irritation, headaches, and respiratory difficulties while working on a stannous and lead sarcophagus. This object was covered with approximately $15 \mathrm{~kg}$ of CDD and stored in a ventilated room. The sublimated CDD was suspected to be the irritant as no specific operation had been performed on the sarcophagus. Two other similar situations are known by the authors. A questionnaire was sent to 15 Swiss conservators-restorers in order to better understand the work practices with CDD (unpublished data). Only two conservators-restorers indicated using the CDD frequently (weekly). One of them reported headaches after long work

${ }^{1}$ Prof. Dr. Matthias Knaut, Deanship, Department of conservation and restoration of archaeological cultural objects, University of Applied Sciences, Berlin. Written communication on 12th may 2009. 
periods with CDD. Respiratory effects following the heating of CDD were also reported spontaneously by another conservator-restorer from the Basel Historical museum (Switzerland). The use of cyclododecane in conservation and restoration is rapidly increasing. However, adequate work practices have not been developed to prevent exposures. In order to develop a targeted prevention, we conducted a short field investigation to characterize CDD exposures and to assess exposure determinants. 


\section{Methods}

Measurements were performed at the laboratory of conservation and restoration of the archeological service in Bern. The work stations were equipped with either ventilated hoods or local exhaust ventilation. Filtering facepiece respirators were made available for both field and laboratory work. The annual consumption of CDD at the laboratory is estimated to maximum 20 $\mathrm{kg}$ and the frequency of use is not more than once per month.

Two typical CDD application methods were investigated: a spray application (heated spray gun) and a brush application. In the latter the CDD was continually maintained at $60^{\circ} \mathrm{C}$ using a hotplate. Both applications were performed by an experienced operator in three indoor and four outdoor scenarios considered relevant to archeological CDD exposures. Indoor measurements were performed on charcoal adsorbent tubes (SKC anasorb CSC226-01) using pocket pumps (1 I/min, Escort Elf Pump, MSA, Pittsburgh, Pennsylvania) for durations ranging from 34 to $49 \mathrm{~min}$. Outdoor measurements, which were mostly involving spray gun application and thus aerosol emission, were performed similarly to some liquid aerosol techniques (Khanh et al. 2009). Sampling was conducted in series, using an open-faced glass fiber filter (SKC 225-7, 37mm) combined with a charcoal adsorbent tube (SKC anasorb CSC226-01, $1 \mathrm{l} / \mathrm{min}$ ). Samples were taken in relation to the nose of the operator (individual sampling). Outdoor measurement duration ranged between 13 to $27 \mathrm{~min}$, corresponding to the treatment of small artifacts. The measurement period includes CDD applications (of typically 5 min.) itself as well as re-heating and refilling operations.

Direct-reading measurements were performed concomitantly to air sampling. Vapors were measured using a photo-ionization detector (Toxi Rae ${ }^{\circledR}$, Rae Systems Inc., Sunnyvale, California, 
USA) located near the nose of the operator. The photoionisation detector was calibrated with CDD prior to the measurements.

Outdoor measurements were performed while using CDD in (1) an open area at ground level, (2) on a vertical wall, simulating archeological work on a vertical plane (see Figure 1), and (3) in an underground staircase, simulating work into an open ditch. Indoor measurements were performed with and without ventilation (ventilated hood). Three measurements were performed for each exposure scenario.

Figure 1 (about here)

Both charcoal tubes and filter cassettes are closed immediately after field sampling and brought back to the laboratory (in a CDD free environment). The filter cassette is then connected to a new charcoal tube (SKC anasorb CSC226-01, $1 \mathrm{l} / \mathrm{min}$ ) and air is pumped through the tube during several hours (while the CDD sublimates). The same desorption and analysis procedure is used for charcoal tubes corresponding to aerosol and vapor fraction. After separation, the front and backup of the charcoal tubes were desorbed using $2 \mathrm{ml}$ of dichloromethane (in ultrasonic bath for 15 minutes). In order to increase recovery, desorption of the front part was carried out a second time, obtaining a final recovery of $80.4 \%$ (LD : $0.4 \mu \mathrm{g} / \mathrm{tube})$.

Samples were analyzed by a gas chromatograph equipped with a flame ionization detector (Varian 3800). The separation was performed on a capillary column (95\% dimethylpolysiloxane polymer, $5 \%$ phenyl groups; $60 \mathrm{~m} \times 0.25 \mathrm{~mm}$ i.d., $0.25 \mu \mathrm{m}$ film thickness) using nitrogen as a carrier gas (flow rate $1.5 \mathrm{ml} / \mathrm{min}$ ). The oven temperature was initially held at $100^{\circ} \mathrm{C}$ during 4 
minutes, then increased to $270^{\circ} \mathrm{C}$ at $15^{\circ} \mathrm{C} / \mathrm{min}$ and held for 4 minutes. The injector temperature was set at $270^{\circ} \mathrm{C}$ and injection was performed with a split ratio of $40: 1$. The flame ionization detector was set at $280^{\circ} \mathrm{C}$ with an air flow rate of $300 \mathrm{ml} / \mathrm{min}$, hydrogen flow rate of $30 \mathrm{ml} / \mathrm{min}$ and a nitrogen makeup flow rate of $30 \mathrm{ml} / \mathrm{min}$. The injected sample volume was $1 \mu \mathrm{l}$. The CDD retention time under these conditions was 16.6 minutes. 


\section{Results and discussion}

CDD concentrations during typical activities are presented in Table 1. The lowest CDD exposures $\left(0.75-0.85 \mathrm{mg} / \mathrm{m}^{3}\right.$ in average) were observed when using a ventilated hood indoor, either during brush or spray gun application. CDD concentrations during brushing without local ventilation (ventilation hood off) were found to be an order of magnitude higher. Surprisingly, outdoor exposure levels were even higher, ranging between 19.5 and $53.9 \mathrm{mg} / \mathrm{m}^{3}$ in average, despite the natural ventilation. These results suggest that exposure to CDD is extremely localized, and achieving exposure control with collective ventilation is unlikely. This may be explained by the physico-chemical properties and the application methods of CDD. When using a spray gun, the pressure drop at the spray nozzle and the contact with the ambient air provoke a rapid condensation into solid phase, generating large amounts of aerosols. To limit this unwanted condensation effect, the operator must maintain a distance of about $5 \mathrm{~cm}$ between the spray nozzle and the artifact bringing the operator to immediate vicinity of the CDD source (Figure 1). This is also true during the brush-on application at ground level, where the operator is bent over the artifact.

Table 1 (about here)

Outdoor CDD exposures tended naturally to increase with confinement e.g. open ditch work, for which a maximum value of $74.4 \mathrm{mg} / \mathrm{m}^{3}$ was found. CDD concentrations in poorly ventilated area are elevated suggesting that vapors, either issued from the primary emission source or from the reemission of deposited material are predominant. Filtering facepiece respirators are therefore not adequate in such situations. 
It should be noted that, although conservative, the "open-ditch" scenario illustrated in Figure 2 leading to the highest exposure levels was not extreme. In practice, exposures may occasionally occur in more enclosed spaces. Being dependant on the specificity of a given archeological site, field application in confined spaces may occur such as in crypts or caves. Moreover, to protect workers from the weather, tents are occasionally put up over the ditches.

CDD sublimes slowly at room temperature, making the artifacts emit vapors a long time after the initial coating. Such delayed exposures should be considered when storing CDD-coated artifacts in poorly ventilated area. Moreover, contaminated materials (tools, clothing, and protective filter) may also be sources of delayed exposures.

Figure 2 (about here) 


\section{Conclusion}

Little attention has been given on CDD safety previously because it was considered as an intermediate product in industry and generally used in enclosed systems. Current work practices in archeology and conservation involves however the direct handling of hot CDD and subsequent exposure to vapors and aerosols. More information is therefore requested on the product acute and chronic toxicity in order to develop adequate permissible exposure limits. Considering that (1) respiratory and CNS symptoms have been reported immediately after using CDD in unfavorable conditions and (2) the more exposing tasks (e.g. brushing, spraying) are usually performed less than once per week and for short periods, local or individual measures to prevent exposures during work with CDD are recommended. Ventilated hoods or local exhaust ventilation must be used whenever possible. Respirators (filtering facepiece) may also be adequate for open field conditions or in ventilated areas. Local extraction, portable enclosures or powered air-purifying respirator should be considered in other cases (e.g. ditch work). CDD coated artifacts as well as tools and protective clothing used during CDD application should be stored in ventilated areas.

\section{Conflict of Interest}

This study has been performed with internal funding only. The authors declare that they have no conflict of interest. 


\section{Acknowledgments}

We want to express our thanks to the whole team from the conservation laboratories at the Archaeological Service of the Canton Bern (Switzerland), and particularly to Christoph Rogalla von Bieberstein, head of the department, and Frédérique-Sophie Tissier. We also thank Dr Cong Khanh Huynh and Philippe Boiteux for their support. We thank above all the late Dr PierreOlivier Droz for his engagement towards the project. 


\section{References}

European Chemicals Bureau, IUCLID (International Uniform ChemicaL Information Database) dataset for cyclododecane, dataset created by the European Commission and distributed online at http://ecb.jrc.cec.eu.int/documents/Existing-Chemicals/IUCLID/DATA SHEETS/294622.pdf (visited October 2010).

European chemical agency (ECHA). (2008) European Commission. Annex XV dossier cyclododecane.http://echa.europa.eu/doc/consultations/svhc/svhc axvrep france pbt cyclodo decane 20083006.pdf (visited December 2009).

Irie D, Sasaki T and Ito R. (1973) Acute toxicities of cyclododecane (CD), tricyclododecane (TCD), naphthaline (NP) and para-dichlorobenzene (PZ). J Med Soc Toho Uni; 20:772- 7.

Khanh Huynh C, Herrera H, Parrat J, Wolf R and Perret V. (2009) Occupational exposure to mineral oil metalworking fluid (MWFs) mist: Development of new methodologies for mist sampling and analysis. Results from an inter-laboratory comparison. J Phys: Conf Ser.;151:17.

Rowe S and Rozeik C. (2008) The uses of cyclododecane in conservation. Reviews in conservation; 9:17-31.

TRGS 900, technical guideline document created by the German Federal Institute for Occupational Safety and Health (BAuA) and distributed online at http://www.baua.de/nn_16806/de/Themen-von-A-Z/Gefahrstoffe/TRGS/pdf/TRGS-900.pdf (visited october 2010). 
Figure 1. Example of a spray application of CDD (outdoor, on a vertical wall)

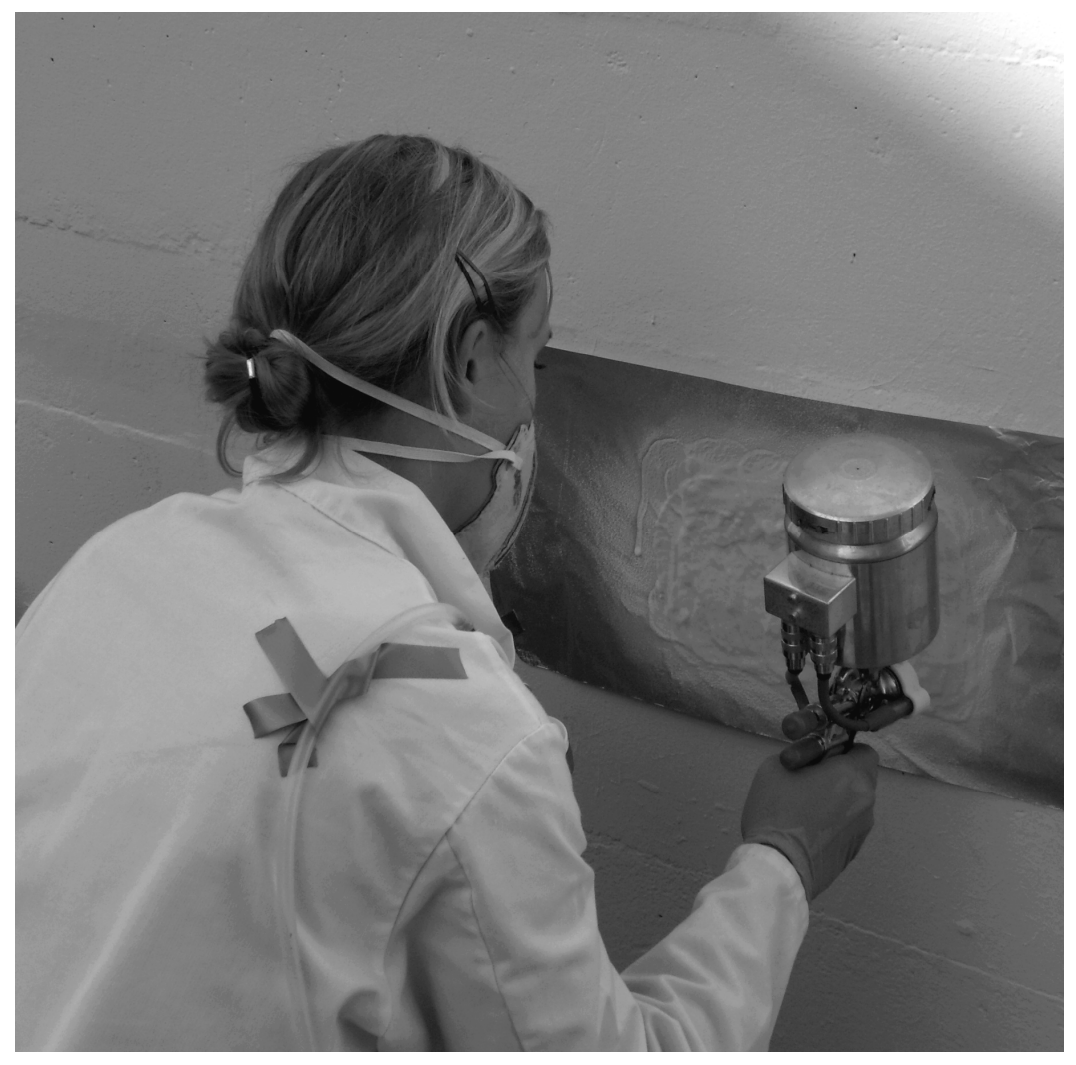


Table 1. Exposure levels to CDD during typical activities

\begin{tabular}{|c|c|c|c|}
\hline \multirow[t]{2}{*}{ Location } & \multirow[t]{2}{*}{ Application method } & \multicolumn{2}{|c|}{ CDD concentration ${ }^{\mathrm{a}}\left[\mathrm{mg} / \mathrm{m}^{3}\right]$} \\
\hline & & Mean $(n=3)$ & range \\
\hline \multirow[t]{3}{*}{ Indoor } & Brush, ventilated hood off & 15.5 & $0.55-40.6$ \\
\hline & Brush, ventilated hood on & 0.85 & $0.53-1.0$ \\
\hline & Spray gun, ventilated hood on & 0.75 & $0.06-1.6$ \\
\hline \multirow[t]{4}{*}{ Outdoor } & Brush, open area & 23.3 & $10.2-40.4$ \\
\hline & Spray gun, open area ${ }^{b}$ & 24.2 & $12.1-40.8$ \\
\hline & Spray gun, vertical wall ${ }^{b}$ & 19.5 & $12.7-24.4$ \\
\hline & Spray gun, open ditch & 53.9 & $30.9-74.4$ \\
\hline
\end{tabular}


Figure 2. $\mathrm{CDD}$ vapor $\left(\mathrm{mg} / \mathrm{m}^{3}\right)$ during the "open-ditch" scenario, showing two successive spray gun applications

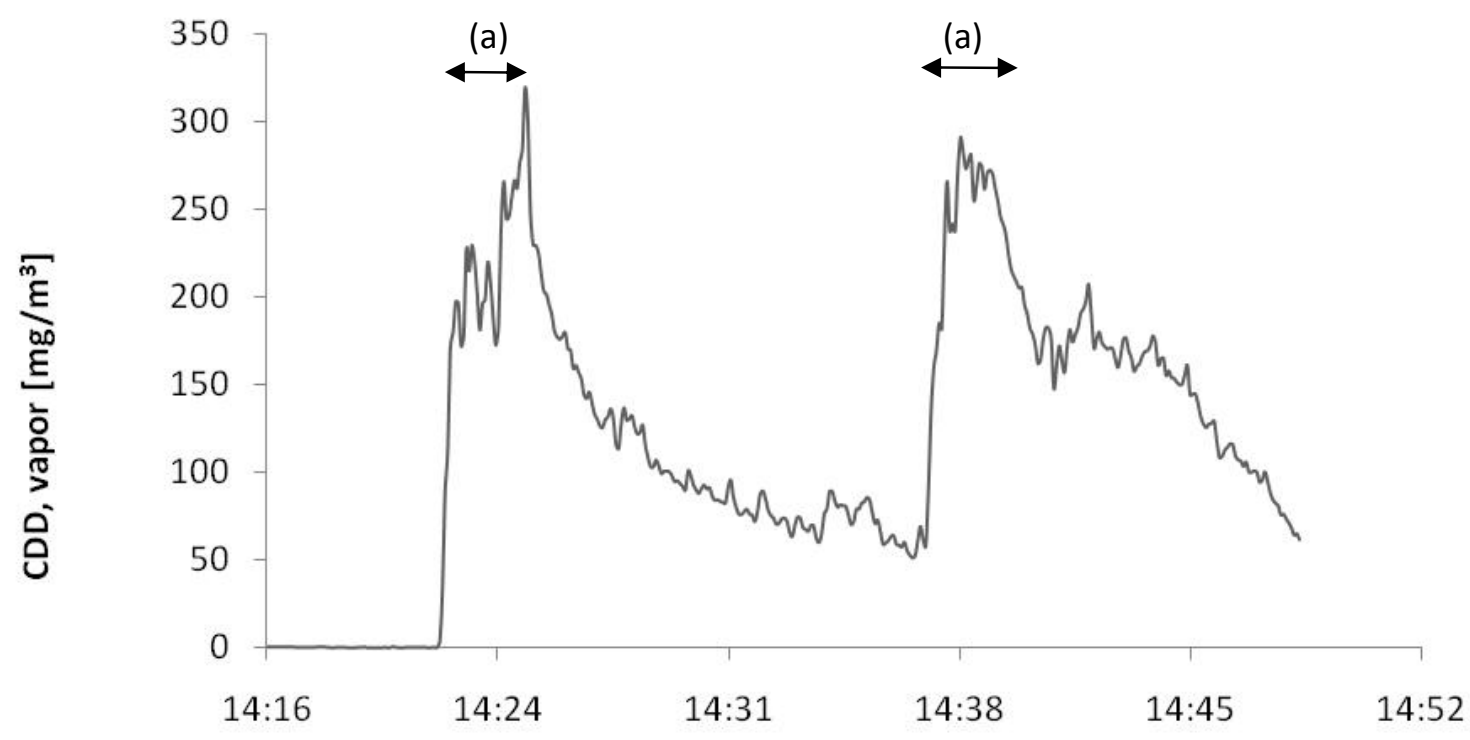

Time [hh:mm]

(a) Spraying periods (14h23-14h25; 14h37-14h40) 